\title{
Identification of Folding Intermediates of Streblin, The Most Stable Serine Protease: Biophysical Analysis
}

\author{
Reetesh Kumar • Pinki Tripathi • \\ Fabio Rogerio de Moraes • Ícaro P. Caruso • \\ Medicherla V. Jagannadham
}

Received: 7 August 2013 / Accepted: 27 September 2013/

Published online: 10 October 2013

(C) The Author(s) 2013. This article is published with open access at Springerlink.com

\begin{abstract}
Streblin, a serine proteinase from plant Streblus asper, has been used to investigate the conformational changes induced by $\mathrm{pH}$, temperature, and chaotropes. The near/far UV circular dichroism activities under fluorescence emission spectroscopy and 8-aniline-1-naphthalene sulfonate (ANS) binding have been carried out to understand the unfolding of the protein in the presence of denaturants. Spectroscopic studies reveal that streblin belongs to the $\alpha+\beta$ class of proteins and exhibits stability towards chemical denaturants, guanidine hydrochloride $(\mathrm{GuHCl})$. The $\mathrm{pH}$-induced transition of this protein is noncooperative for transition phases between $\mathrm{pH} 0.5$ and 2.5 (midpoint, 1.5) and $\mathrm{pH} 2.5$ and 10.0 (midpoint, 6.5). At pH 1.0 or lower, the protein unfolds to form acid-unfolded state, and for $\mathrm{pH} 7.5$ and above, protein turns into an alkaline denatured state characterized by the absence of ANS binding. At $\mathrm{pH} 2.0$ $(1 \mathrm{M} \mathrm{GuHCl})$, streblin exists in a partially unfolded state with characteristics of a molten globule state. The protein is found to exhibit strong and predominant ANS binding. In total, six different intermediate states has been identified to show protein folding pathways.
\end{abstract}

Keywords Sequential unfolding $\cdot$ Streblin $\cdot$ Streblus asper $\cdot$ Biophysics $\cdot$ Molten globule

\section{Abbreviations}

CD Circular dichroism

R. Kumar $\cdot$ P. Tripathi $\cdot$ M. V. Jagannadham $(\bowtie)$

Molecular Biology Unit, Institute of Medical Sciences, Banaras Hindu University, Varanasi, India e-mail: jvm@bhu.ac.in

R. Kumar

e-mail: reeteshmbu@gmail.com

R. Kumar • F. R. de Moraes • Í. P. Caruso

Instituto de Biociências, Letras e Ciências Exatas (IBILCE), Universidade Estadual Paulista "Julio de Mesquita Filho", São José do Rio Preto, SP, Brazil

Present Address:

R. Kumar

Department of Physics, Universidade Estadual Paulista "Julio de Mesquita Filho",

São José do Rio Preto, SP, Brazil 


$\begin{array}{ll}\text { UV } & \text { Ultraviolet } \\ \text { GuHCl } & \text { Guanidine hydrochloride } \\ \text { Fu } & \text { Fraction unfolded } \\ \text { ANS } & \text { 8-aniline-1-naphthalene sulfonate }\end{array}$

\section{Introduction}

Accretion of a large number of experimental studies for solving the mechanism of protein folding is still a major challenge to the structural biologists and biophysicists together. Such studies may gain insight into the molecular origin of enzyme stability that, in turn, can be used to intend protocols with distinctive properties for food biotechnological and pharmacological applications. Protein immovability is the result of external variables, such as $\mathrm{pH}$, temperature, ionic strength, and various solvent compositions as they interrupt or interfere with different kind of contacts that accounts for its intrinsic stability. Therefore, a quantitative analysis of the role of such variations in the arrangement of the structure of the protein is a precondition to present the driving forces that are accountable for the conformational stability. Such studies involve the monitoring of conformational changes due to perturbation of a protein solution by foreign agents, such as acid, guanidine hydrochloride $(\mathrm{GuHCl})$, and temperature. Unfolding of many proteins, that have been studied so far, can be described in terms of a two-state model [1], where only folded and unfolded states of the protein exist in rapid equilibrium without any observable intermediates. Studying the nature of the intermediate structures on the unfolding and refolding pathways of the protein may have elementary importance in understanding the protein folding problem [2] and mis-folding diseases. Therefore, native-like structures accumulating in the unfolding pathway of proteins can potentially be in vivo protein folding intermediates and can provide an insight into the fundamental free energy relationship in protein folding processes [3]. It can also contribute to the understanding of protein mis-folding diseases, such as Alzheimer's, Parkinson's, and prion diseases $[4,5]$. The medical, pharmaceutical, and industrial applications of proteins, however, basically rely on the present knowledge of their folding, unfolding, and refolding. The folding of a protein is influenced primarily by its amino acid sequence and the cellular environment surrounding the polypeptide chain [6]. The unfolding of small proteins simply follows a twostate transitions between its unfolded state and its native or folded state $(\mathrm{N})$, depending on temperature, $\mathrm{pH}$, denaturant concentration, etc. [7]. Chemical and thermal denaturations of proteins are standard techniques in protein biochemistry to determine protein folding and unfolding equilibrium and kinetics [8-11]. It is now an established fact that the folding of large globular proteins is characterized through some kinetic intermediates with the properties similar to molten globule state reported for the folding process of many proteins $[8,12]$. Characterization of folded and partly folded intermediate states of proteins is the central idea to understand the protein stability and folding, and thus, the identification and structural characterization of intermediate states, populated during the folding process of many proteins, have received considerable attention. An understanding of the structural and thermodynamic properties of such intermediate states is expected to provide insight into the factors that are involved in guiding the pathway of the folding. In line to our previous study of general folding aspects of plant serine proteases [13], conformational studies in solution have been initiated with streblin in the present study. Streblin is a novel plant serine protease isolated from Streblus asper plant. It is a highly stable $64 \mathrm{kDa}$ protein and contains three tryptophans and seven tyrosines [13].

By using circular dichroism (CD), we show the presence of $\alpha$ and $\beta$ structures on streblin, belonging to $\alpha+\beta$ class of protein. The unfolding behavior of streblin has been examined in the presence of chemical denaturant $(\mathrm{GuHCl}), \mathrm{pH}$, and temperature. Temperature- and GuHClinduced denaturation of streblin is expected to show deviations from the two-state mechanisms, 
suggesting the presence of intermediate state [14-16]. Several intermediates with distinct spectroscopic properties are also populated under various conditions. The present investigation, however, sheds light on the biophysical properties of streblin as an endeavor to establish the relationship between its structure and function and also the basis and rationale behind its distinct physiochemical properties. The conformational stabilities of the native protein as well as intermediate states have been assessed from their unfolding profiles and compared throughout this study. Streblin, as a highly stable serine protease, would be potentially important for biotechnology and pharmaceutical industries.

\section{Materials and Methods}

Streblin was purified from fresh latex of $S$. asper plant (family Moraceae) [13]. Concentration of the enzyme was determined using an extinction coefficient $\left(\in_{280}^{1 \%}\right)$ of 5.29 [17]. The hydrophobic dye, ANS, and $\mathrm{GuHCl}$ were purchased from Sigma Chemicals, USA. Concentrations of $\mathrm{GuHCl}$ solutions were determined from the refractive index of the solution [18], while other reagents used were also of analytical grade prepared in double distilled water. The $\mathrm{pH}$ denaturation, hydrolyzing activity, and ability to bind with hydrophobic patches with ANS fluorescent dye [19] was monitored as described elsewhere [17].

\section{Absorbance Spectroscopy}

Absorbance spectroscopy measurements were calibrated on a Beckman DU-640B spectrophotometer. The instrument was operated with a constant temperature cell holder; protein concentration for all absorbance measurements was between 9 and $10 \mu \mathrm{M}$, and the desired spectra were recorded between 240 and $320 \mathrm{~nm}$.

\section{Spectropolarimetry}

Circular dichroism measurements were performed on a spectropolarimeter (Jasco J 500A) equipped with a constant temperature cell holder using a Julabo F 25 water bath. The instrument was calibrated using ammonium camphorsulfonate for spectropolarimetry experiments. The conformational changes in the secondary and tertiary structure of the protein were monitored in the region between 200-260 and 260-320 nm, respectively, with protein concentrations of 6 and $36 \mu \mathrm{M}$. After subtracting appropriate blanks, mean residue ellipticities were calculated following [20] as:

$$
[\theta] \mathrm{MRW}=\theta \mathrm{obs} \mathrm{MRW} / 10 \mathrm{cl}
$$

Where, $\theta$ obs is observed ellipticity in degrees, MRW is mean residue weight, $c$ is concentration of protein (grams per cubic meter), and 1 is path length in centimeters. A mean residue molecular weight 110 was used. Sensitivities of 1 and $2 \mathrm{~m} / \mathrm{cm}$ (millidegrees per centimeter) were used for far-ultraviolet (UV) and near-UV measurements, respectively.

\section{Fluorescence Spectroscopy}

Fluorescence measurements were carried out on a Perkin Elmer LS-50B spectrofluorimeter equipped with a constant temperature cell holder using a Julabo F 25 water bath controller. 
Protein concentration was kept at $2 \mu \mathrm{M}$ for all the measurements. Tryptophan and tyrosine were selectively excited at $292 \mathrm{~nm}$, and the emission were recorded from 300 to $400 \mathrm{~nm}$ with 10 and $5 \mathrm{~nm}$ slit widths for excitation and emissions.

\section{Assay for Enzyme Activity}

The hydrolyzing activity of streblin under various conditions of $\mathrm{pH}$ or in the presence of chemical denaturant was monitored using the denatured natural substrate azoalbumin following the procedure previously described [17]. The enzyme was incubated overnight in denaturants before assays.

\section{$\mathrm{pH}$ Denaturation of Streblin}

Acid denaturation of streblin was carried out as a function of $\mathrm{pH}$ using $\mathrm{KCl}-\mathrm{HCl}(\mathrm{pH} 0.5-$ 1.5), Gly- $\mathrm{HCl}(\mathrm{pH} 2.0-3.5)$, sodium acetate $(\mathrm{pH} 4.0-5.5)$, sodium phosphate $(\mathrm{pH}$ 6.0-8.0), Tris- $\mathrm{HCl}$ ( $\mathrm{pH} 8.5-10.5)$, and Gly- $\mathrm{NaOH}$ ( $\mathrm{pH} 11.0-12.5)$. Concentrations of all buffers were $50 \mathrm{mM}$. A stock solution of the protein was added to the appropriate buffer and the mixture was incubated for $24 \mathrm{~h}$ at $25^{\circ} \mathrm{C}$. The final $\mathrm{pH}$ and concentration of the protein in each sample were measured again.

\section{ANS Binding Assay}

Exposure of hydrophobic surfaces in the enzyme was measured by its ability to bind to the fluorescent dye 8-aniline-1-naphthalene sulfonate (ANS) as described by Semisotnov et al. [19]. Streblin was stable up to $40 \%$ methanol [13]; therefore, since ANS dissolves in a minimum amount of methanol, it does not affect the structure of the protein.

\section{Guanidine Hydrochloride-Induced Unfolding}

Protein sample was incubated at a desired concentration of $\mathrm{GuHCl}$ for approximately $24 \mathrm{~h}$ at $25{ }^{\circ} \mathrm{C}$ to achieve equilibrium. The final concentration of the protein and denaturants, in each sample, were determined by spectrophotometry and refractive index measurements, respectively. Data are expressed in terms of fraction unfolded $(\mathrm{Fu})$ as calculated from the given equation:

$$
\mathrm{Fu}=\mathrm{Fobs}-\mathrm{Fn} / \mathrm{Fu}-\mathrm{Fn}
$$

Where Fobs is the observed value of the signal at a given denaturant concentration and Fn and $\mathrm{Fu}$ are the values of native and unfolded protein, respectively.

\section{Thermal Unfolding}

Temperature-induced denaturation of the enzyme, under given conditions, was performed as a function of increasing temperature. Protein samples were incubated at the desired temperature for $15 \mathrm{~min}$ before measurements. The actual temperature of the sample in the cuvette was obtained with a thermocouple using a digital multimeter. 


\section{Result and Discussion}

\section{Absorbance Spectra}

The near-UV (250-320 nm) absorbance spectra of the proteins are based mainly on the absorbance of aromatic amino acids such as tryptophan, tyrosine, and phenylalanine. The spectral properties of a protein in the molecular environment are based on the mobility of its chromophoric residues [21]. Therefore, all the investigations are carried out by circular dichroism, fluorescence, and activity assays as measures of changes.

\section{Fluorescence Spectra}

Fluorescence spectra impart a perceptive mean of illustrating the conformation of the proteins. The spectrum is based on the polarity of the environment of tyrosine and tryptophan residues and their interactions. Basically, the tryptophan emission spectra reflects the average environment of the tryptophan, and principally the red shift, when chromophores get exposed to solvent and the quantum yield decreases due to its interaction with quenching agent either in the solvent or in the protein itself [22, 23].

The fluorescence spectra of streblin, under native conditions, at $\mathrm{pH} 2.0,12.0$ and in $6 \mathrm{M}$ $\mathrm{GuHCl}$ are shown in Fig. 1. The intrinsic fluorescence spectrum of streblin at neutral $\mathrm{pH}$ has a maximum emission at $348 \mathrm{~nm}$, indicating that the tryptophan is exposed to solvents. Spectra of the unfolded enzymes in $6 \mathrm{M} \mathrm{GuHCl}$ remains similar in shape, but the emission maximum shifted from 348 to $356 \mathrm{~nm}$ with an increase in the intensity by $37 \%$. Further, as compared to the native protein, the intensity of fluorescence decreases by 47 and $6 \%$ at $\mathrm{pH} 2.0$ and $\mathrm{pH} 12.0$, respectively.

\section{Circular Dichroism}

The far-UV CD spectra of streblin under different conditions is shown in Fig. 2a. The native spectra showed peaks at around 220-222 nm and at $208 \mathrm{~nm}$, which suggest that streblin

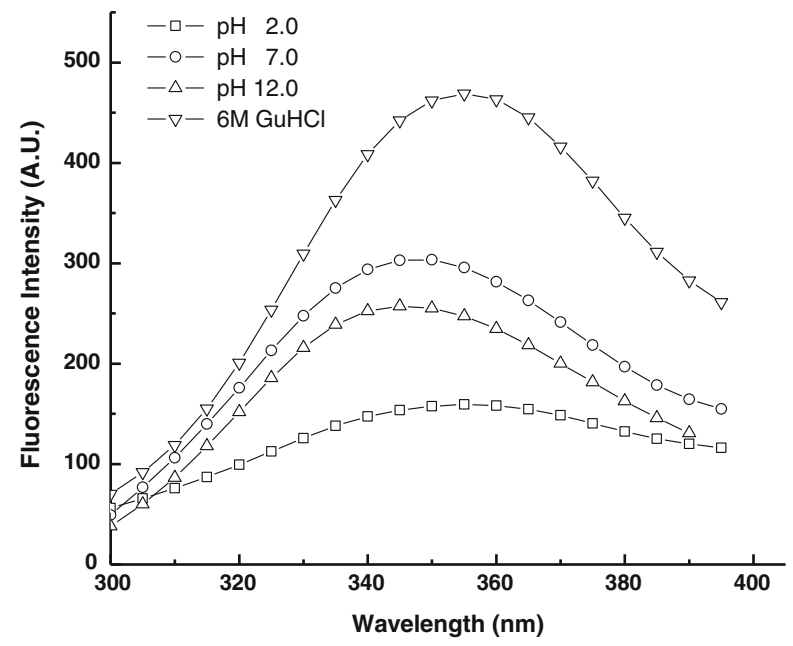

Fig. 1 Fluorescence spectroscopy of streblin. Intrinsic fluorescence spectra were recorded at pH 7.0, pH 2.0, $\mathrm{pH} 12.0$, and in the presence of $6 \mathrm{M} \mathrm{GuHCl}$. The sample was incubated for $24 \mathrm{~h}$ at $25^{\circ} \mathrm{C}$ before the measurements. The protein concentration was $2.0 \mu \mathrm{M}$ 

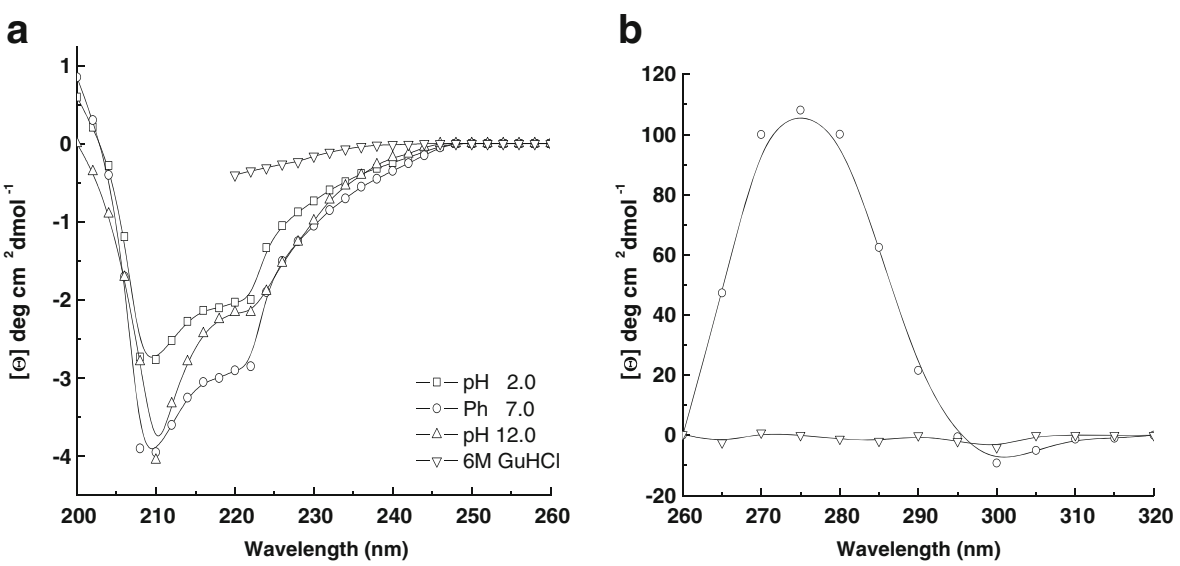

Fig. 2 Circular dichroism spectra of streblin a far-UV spectra was recorded at $\mathrm{pH} 7.0, \mathrm{pH} 2.0, \mathrm{pH} 12.0$, and in the presence of $6 \mathrm{M} \mathrm{GuHCl} ; \mathbf{b}$ near-UV spectra at $\mathrm{pH} 7.0$ and in the presence of $6 \mathrm{M} \mathrm{GuHCl}$. The sample was incubated for $24 \mathrm{~h}$ at $25^{\circ} \mathrm{C}$ before the measurements. The protein concentration was $6.0 \mu \mathrm{M}$ for far-UV and $35.0 \mu \mathrm{M}$ for near-UV

belongs to the $\alpha+\beta$ class of proteins [24]. The mean residue ellipticity at $222 \mathrm{~nm}$ and at neutral $\mathrm{pH}$ was $-3.0 \pm 0.5 \times 10^{-3} \mathrm{deg} \mathrm{cm}^{2} /$ day mol. The secondary structural features of the enzyme are completely lost in $6 \mathrm{M} \mathrm{GuHCl}$ with disappearance of all prominent peaks.

Near-UV CD spectra (Fig. 2b) help in detecting the tertiary structure of the protein. The spectrum depends mainly on the protein tertiary structure, including their solvent accessibility. The residues side chain easily interacts with the side chain amide, carboxylate group, and the peptide bond [25]. In the aromatic region, streblin exhibits a positive peak at 278$280 \mathrm{~nm}$ and mild negative ellipticity at $298-300 \mathrm{~nm}$. It suggests that the tyrosine and phenylalanine do not contribute to the CD spectra of proteins, and this negative spectrum probably originates from tryptophan residues located in different chemical environment. However, the finer structure suggests the presence of many of the Phe-, Tyr-, and Trp-side chains, ordered in native structure, but disordered under completely denatured conditions. In the presence of $6 \mathrm{M} \mathrm{GuHCl}$, streblin loses all structural features with complete disappearance of all the prominent peaks. This informs that aromatic regions in the unfolded state side chains are generally disordered in this condition.

\section{pH-Induced Unfolding}

The structural and functional changes in streblin upon $\mathrm{pH}$-induced unfolding were followed by activity assay, fluorescence, and $\mathrm{CD}$ measurements over a wide range of $\mathrm{pH}$. The enzyme retains proteolytic activity in the $\mathrm{pH}$ range of 7.0-12.0 and significant amount of secondary structure is retained up to $\mathrm{pH} 4.0$, followed by a gradual decrease in ellipticity when $\mathrm{pH}$ was further lowered (Fig. 3a-b). These declines in ellipticity are due to repulsion of coulombic forces from the positive charges of the polypeptide chains [26]. The changes in ellipticity follow a half bell shape in the range of $\mathrm{pH} 0.5-4.0$ to reveal that all the prominent peaks are lost. The structural changes of streblin according to $\mathrm{pH}$ are indicated by shifts in ellipticity as shown in Fig. 3b. The first transition from the native $(\mathrm{N})$ to an unfolded state occurs at $\mathrm{pH} 4.0$ 1.0. Such loss of secondary structure as well as reduced activity represents the enzyme acidunfolded state (UA). This $\mathrm{pH}$ effect upon protein folding can be balanced in the presence of anions, which bind to the positively charged sites and lead to formation of partially folded 


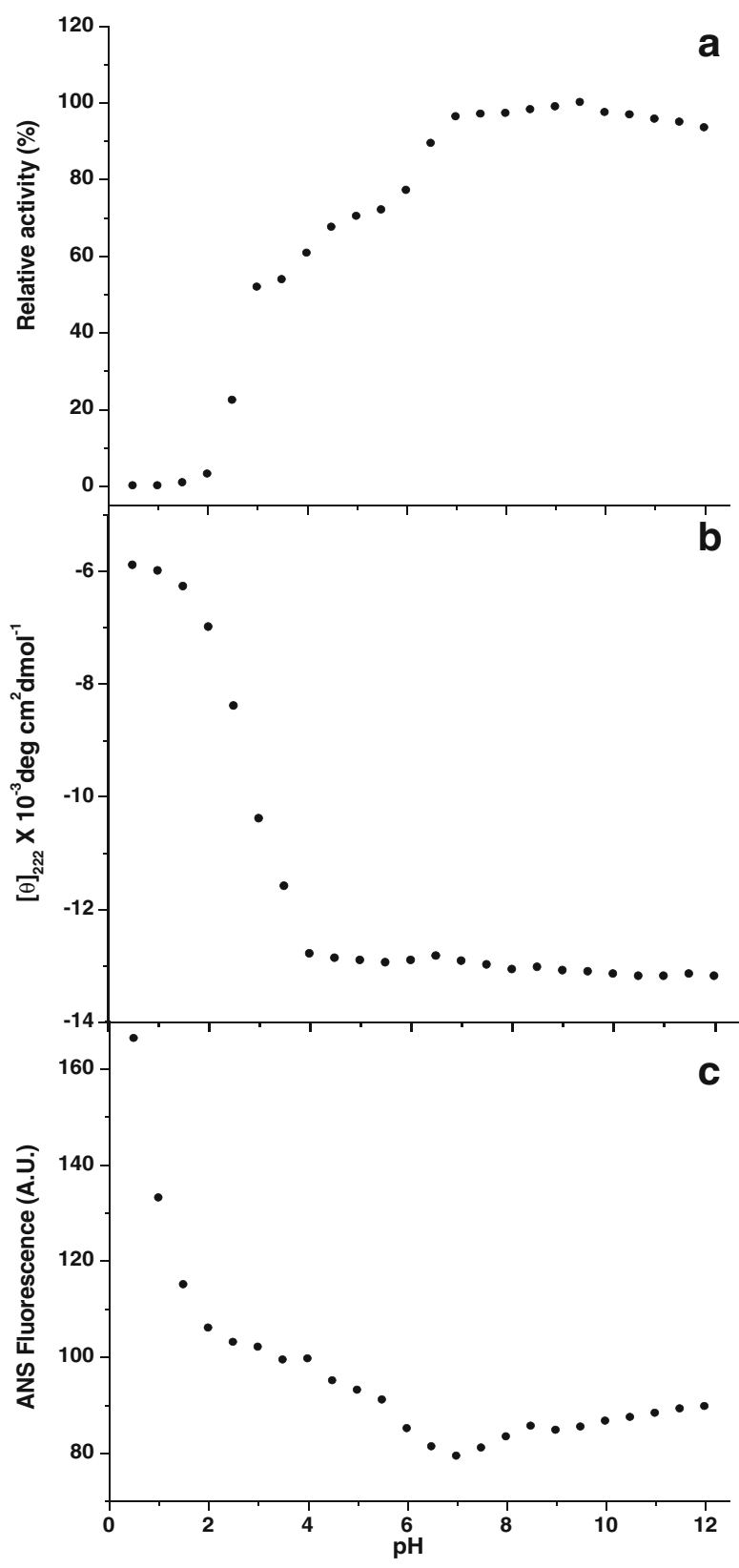

Fig. $3 \mathrm{pH}$-induced conformational changes in streblin. a The residual proteolytic activity, b ellipticity at $222 \mathrm{~nm}$, and $\mathbf{c}$ ANS binding to streblin as a function of $\mathrm{pH}$. The samples were incubated for $24 \mathrm{~h}$ at $25^{\circ} \mathrm{C}$ before the measurements were taken (see "Materials and Methods" for details)

intermediates [27-30]. The far-UV spectra of streblin in $\mathrm{pH}$ range 12.0-4.0 remains unchanged, and the spectra reveal two distinct peaks, one at $222 \mathrm{~nm}$ and the other at $208 \mathrm{~nm}$.

The exposure of any hydrophobic patches is obscured inside the enzyme in the native state; however, $\mathrm{pH}$ unfolding was monitored by ANS binding of the protein. ANS, also 
known as polarity sensitive extrinsic fluorescence probe, has been frequently used to detect equilibrium unfolding intermediates. Such simple binding to hydrophobic patches can provide insights into an apparently complicated problem of protein folding [31]. The level of ANS binding to streblin at different $\mathrm{pH}$ is shown in Fig. 3c. ANS binding to the enzyme is maximum at $\mathrm{pH} 0.5$ in comparison to that in the native and completely unfolded states. ANS fluorescence intensity increases exponentially at this $\mathrm{pH}$, and emission maximum shifted to the shorter wavelength from 499 to $487 \mathrm{~nm}$ when compared to alkaline denatured state. Up to $\mathrm{pH} 7.5$, streblin shows no hydrophobic patches due to the absence of ANS binding. This condition shows the alkaline denatured state (UB) at $\mathrm{pH} 7.5$ and above $\mathrm{pH}$, as shown in Fig. 3c.

Streblin fluorescence at different $\mathrm{pH}$ was also monitored, and the intensity and emission maximum changes are shown in Fig. 4. These changes reveal information about the solvent accessibility and hydrophobicity of aromatic residues. The excitation wavelength at $292 \mathrm{~nm}$ was chosen to selectively excite tryptophan residues [32]. Upon $\mathrm{pH}$ decreasing from neutrality to the acidic, the $\mathrm{pH}$-induced transition is noncooperative and exhibit a biphasic nature with one transition between $\mathrm{pH} 0.5$ and 2.5 with a midpoint at $\mathrm{pH} 1.5$ approximately. Another transition is seen between $\mathrm{pH} 2.5$ and 5.0 with a midpoint at $\mathrm{pH} 4.0$ approximately. The shape of the spectrum remains the same at all $\mathrm{pH}$ values, but a blue shift of $3 \mathrm{~nm}$ in emission maximum along with an increase in fluorescence intensity is observed when $\mathrm{pH}$ was reduced from 2.5 to 0.5. By increasing the $\mathrm{pH}$, another transition occurs from $\mathrm{pH} 5.0$ to 10.0 with a midpoint at $\mathrm{pH}$ 7.0. However, above $\mathrm{pH}$ 5.0, the protein has high proteolytic activity (Fig. 3a) and the induced transition is cooperative and have a midpoint at $\mathrm{pH}$ 7.0. These observations may be further analyzed in future studies for better interpretation of biophysical data.

\section{GuHCl-Induced Unfolding}

Analysis of the denaturation curves by $\mathrm{GuHCl}$ can provide a measure of the conformational stability to the protein [18]. Under natural conditions, GuHCl-induced unfolding results in sigmoidal curves as seen by different probes (Fig. 5a). All the structural changes occurred between 3 and $5 \mathrm{M} \mathrm{GuHCl}$ with a transition midpoint at $3.25 \pm 0.1 \mathrm{M} \mathrm{GuHCl}$. The loss of proteolytic activity coincided with the loss in secondary structure (Fig. 3), reflecting a good correlation between the activity and structural integrity of the molecule.

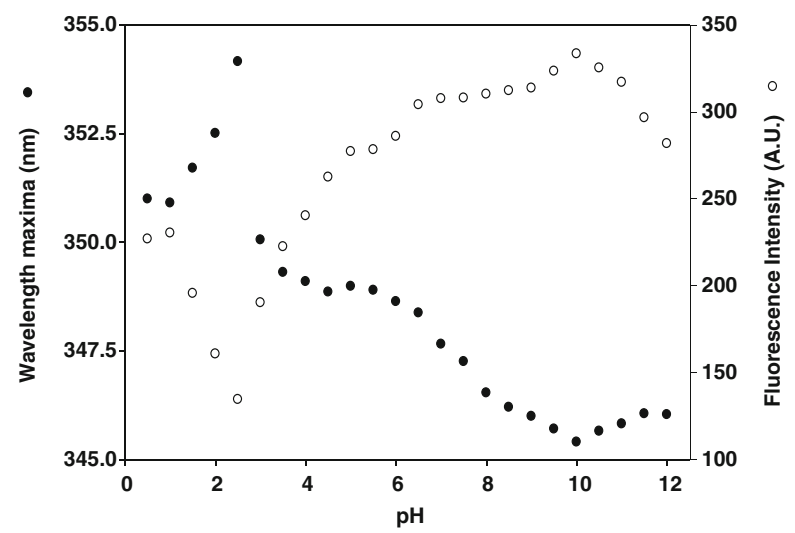

Fig. 4 Effect of $\mathrm{pH}$ on the intrinsic fluorescence of streblin. Fluorescence emission maximum (dark-filled circle) and fluorescence intensity (open circle). Protein was incubated for $24 \mathrm{~h}$ at a particular $\mathrm{pH}$ before the measurements 

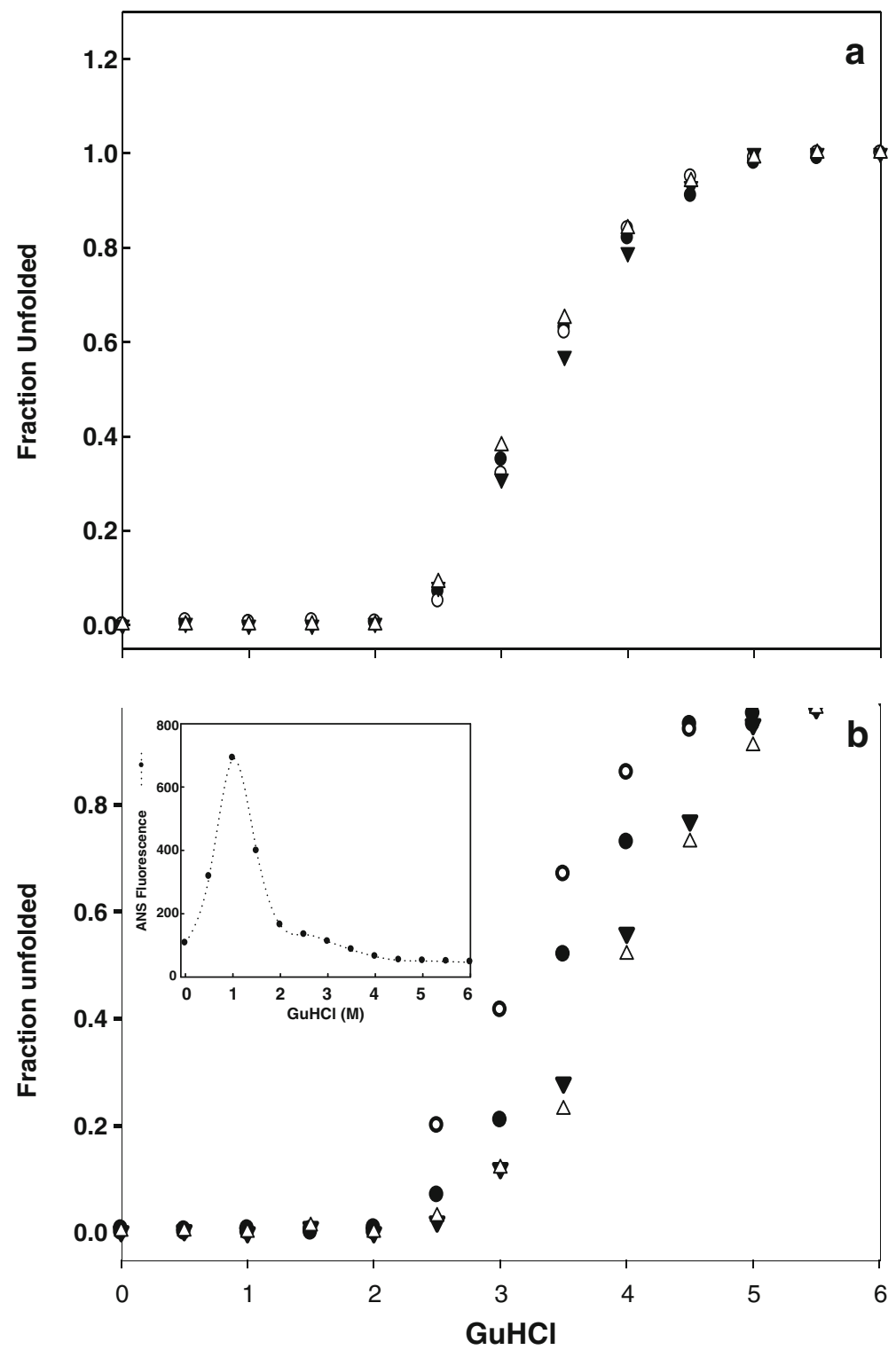

Fig. 5 Equilibrium $\mathrm{GuHCl}$ denaturation of streblin. GuHCl-induced unfolding of streblin at pH 7.0 (a) and 2.0 (b) were carried out. The data were normalized and analyzed according to Equation [2] (see "Materials and Methods"). The symbols denote the wavelength maxima (open circle), fluorescence intensity (dark-filled circle), far-UV CD (black down-pointing triangle), and near-UV CD (white up-pointing triangle) in this respect. The inset shows in $\mathbf{b}$ ANS binding as a function of $\mathrm{GuHCl}$ concentration

Streblin was highly stable with no irreversible loss of proteolytic activity within $\mathrm{pH}$ ranging between 3.0 and 12.0 [13]. It was, therefore, interesting to check the structural integrity of the molecule at low $\mathrm{pH}$. A slight change in the structure upon acidification should reflect its stability and should be observed in the presence of denaturants. At lower concentrations of $\mathrm{GuHCl}$, at $\mathrm{pH} 2.0$, streblin tends to aggregate and the amount of aggregation being dependent 
on the concentration of $\mathrm{GuHCl}$. The $\mathrm{GuHCl}$-induced unfolding of streblin at $\mathrm{pH} 2.0$ is shown in Fig. 5b. The unfolding transition is cooperative and non-coincidental, with complete loss of structure at $5 \mathrm{M} \mathrm{GuHCl}$. Similarly, the fluorescence intensity and maxima show a cooperative transition with a red shift of $3 \mathrm{~nm}$ in the wavelength. Emission maximum of intrinsic fluorescence is seen upon chemical-induced unfolding from the native to the denatured state (D). The red shift in emission maximum upon unfolding coincides with the loss in secondary structure and increasing exposure of tryptophan residues to a polar environment, which is characteristic of protein unfolding $[22,23]$. GuHCl-induced unfolding, when monitored by changes in the secondary structure, fluorescence intensity, and wavelength maxima, is cooperative but the unfolding transitions by these probes are non-coincidental in nature. Such transitions indicate the probable existence of intermediate states in unfolding pathways [33]. The transition midpoint of denaturation followed by wavelength maxima, fluorescence intensity, far- and near-UV, and ellipticity are approximately $3.15 \pm 0.1,3.45 \pm 0.1,3.90 \pm 0.1$, and $3.86 \pm 0.1$, respectively (Table 1). Upon complete unfolding at $5 \mathrm{M} \mathrm{GuHCl}$, the fluorescence intensity increases, whereas the emission maxima shift from 354 to $357 \mathrm{~nm}$ (data not shown).

When ANS fluorescence was used to monitor the denaturation process, the decrease in ANS fluorescence intensity coupled with red shift in its wavelength maximum was found, as shown in Fig. 5b. High ANS fluorescence intensity at $1 \mathrm{M} \mathrm{GuHCl}$ indicates the exposure of hydrophobic residues in this state, which is in line with the idea of molten globule state (MG) at the particular $\mathrm{GuHCl}$ concentration. However, at $\mathrm{pH} 2.0$, the protein became partially folded and behaved as an intermediate between molten globule and native state. This was confirmed by ANS binding capacity and reveals that it has intermediate affinity as compared to the native and molten globule states (data not shown). This state is, therefore, defined as pre-MG state. At lower $\mathrm{pH}, \mathrm{GuHCl}$ interacts with the partially unfolded molecules and resulted in increased stability of the protein [34-36]. As streblin at lower $\mathrm{pH}$ is

Table 1 Thermodynamic parameters of streblin under various conditions

\begin{tabular}{|c|c|c|c|}
\hline Condition & Denaturant & Method & $\begin{array}{l}\text { Transition midpoint } \\
\mathrm{Cm}(\mathrm{M})\end{array}$ \\
\hline \multirow[t]{4}{*}{$\mathrm{pH} 2.0$} & \multirow[t]{4}{*}{$\mathrm{GuHCl}$} & Wavelength maxima & $3.15 \pm 0.1$ \\
\hline & & Fluorescence intensity & $3.45 \pm 0.1$ \\
\hline & & $\mathrm{CD}[\theta]_{222}$ & $3.90 \pm 0.1$ \\
\hline & & $\mathrm{CD}[\theta]_{278}$ & $3.86 \pm 0.1$ \\
\hline \multirow[t]{4}{*}{$\mathrm{pH} 7.0$} & \multirow[t]{4}{*}{$\mathrm{GuHCl}$} & Wavelength maxima & $3.25 \pm 0.1$ \\
\hline & & Fluorescence intensity & $3.24 \pm 0.1$ \\
\hline & & $\mathrm{CD}[\theta]_{222}$ & $3.25 \pm 0.1$ \\
\hline & & $\mathrm{CD}[\theta]_{278}$ & $3.22 \pm 0.1$ \\
\hline \multirow[t]{3}{*}{$\mathrm{pH} 7.0$} & \multirow[t]{3}{*}{ Temperature } & Wavelength maxima & $76.75 \pm 0.25$ \\
\hline & & $\mathrm{CD}[\theta]_{222}$ & $76.75 \pm 0.25$ \\
\hline & & $\mathrm{CD}[\theta]_{278}$ & $76.76 \pm 0.25$ \\
\hline \multirow[t]{6}{*}{$\mathrm{pH} 2.0$} & \multirow[t]{6}{*}{ Temperature } & Wavelength maxima & $59.45 \pm 0.25(\mathrm{Cm} 1)$ \\
\hline & & & $89.95 \pm 0.25(\mathrm{Cm} 2)$ \\
\hline & & $\mathrm{CD}[\theta]_{222}$ & $59.44 \pm 0.25(\mathrm{Cm} 1)$ \\
\hline & & & $90.00 \pm 0.25(\mathrm{Cm} 2)$ \\
\hline & & $\mathrm{CD}[\theta]_{278}$ & $59.45 \pm 0.25(\mathrm{Cm} 1)$ \\
\hline & & & $88.90 \pm 0.25(\mathrm{Cm} 2)$ \\
\hline
\end{tabular}


partially unfolded, the $\mathrm{Gu}^{+}$and $\mathrm{Cl}^{-}$can easily penetrate the interior sites of the native enzyme and interact with charged residues, increasing the overall stability and favoring folding of the polypeptide. Anions also stabilize molten globule states as in the case of cytochrome $\mathrm{c}$ and apomyoglobulin at low $\mathrm{pH}$ [29], where the protein and the intermediate are positively charged as opposed to the native state. The refolding and stabilization are expected due to the specific stabilizing interactions between the intermediate state and $\mathrm{GuHCl}$, which causes electrostatic shielding through an ionic strength effect or from an effect on the water surface [37]. In addition to this, at lower concentrations, $\mathrm{GuHCl}$ induces refolding of the proteins [38]. Up to $2 \mathrm{M}$ and higher $\mathrm{GuHCl}$ concentration, both the parameters of ANS fluorescence remain unaffected, reflecting no conformational change in the protein. For complete unfolding at $5 \mathrm{M} \mathrm{GuHCl}$, the fluorescence intensity greatly decreases, whereas the maximum of the emission shifts back to $\approx 507 \mathrm{~nm}$ (data not shown). The shift of emission maximum reveals the changes due to dissociation of the probe from proteins upon its unfolding. Further, ANS binding to streblin at $\mathrm{pH} 7.0$ and above suggests the absence of surface hydrophobic patches since no ANS binding was observed.

\section{Thermal Unfolding}

Temperature is the most classical mode of protein denaturation method, and it can induce structural changes and hence provide ample information. Temperature-induced conformational changes of streblin under different $\mathrm{pH}$ conditions were monitored by corresponding changes in various spectral parameters. Under the neutral condition ( $\mathrm{pH} 7.0)$, temperatureinduced unfolding of the enzyme followed a single transition with a transition midpoint (Tm) around $76.75 \pm 0.5{ }^{\circ} \mathrm{C}$ (Fig. 6a). Thus, at this $\mathrm{pH}$, the enzyme was in the native state without any significant loss in structure or activity up to $75.0 \pm 0.5^{\circ} \mathrm{C}$. At $\mathrm{pH} 2.0$, where the enzyme is in a pre-molten globule state, the unfolding transitions followed by far-UV and near-UV CD are noncooperative and coincidental (Fig. 6b). The biphasic transitions show the presence of two structural entities, possibly domains, of different stable states. The transition midpoints corresponding to these structural variants are $59.45 \pm 0.25$ and 88.95 $\pm 0.25{ }^{\circ} \mathrm{C}$. The details of all transition midpoints are summarized in Table 1 . The first transition corresponds to unfolding of less structured and less stable part of the protein at $\mathrm{pH} 2.0$ whereas the second transition corresponds to unfolding of more structured and more stable part. This indicates that the molten globule-like state exists in the first phase of transition, and then it became less stable as the temperature increases at $\mathrm{pH}$ 2.0.

\section{Conclusion}

Streblin is a novel serine protease from the latex of medicinally important plant $S$. asper. The study of intermediates of folding pathway is essential to understand the protein folding mechanism. The unfolding of streblin was followed by various spectroscopic techniques using temperature, $\mathrm{pH}$, and chemical denaturation. We describe a total of six different folding states: (a) the native streblin (N) at neutral $\mathrm{pH}$ with rigid tertiary structure, proteolytic activity, and hydrophobic residues on the inner side of protein lacking ANS binding affinity; (b) the pre-MG state at $\mathrm{pH} 2.0$ with lack of tertiary structure and proteolytic activity, appreciable secondary structure, and partial ANS binding; (c) the acid-unfolded state (UA) with somewhat less secondary structure than pre-MG state with substantial more ANS binding; (d) the alkaline denatured state (UB state) almost absent ANS binding and stable up to $\mathrm{pH} 12.0$; (e) the molten globule state (MG) at pH 2.0 with $1 \mathrm{M}$ $\mathrm{GuHCl}$ and exceptionally high ANS binding of hydrophobic patches buried outside of streblin; (f) 


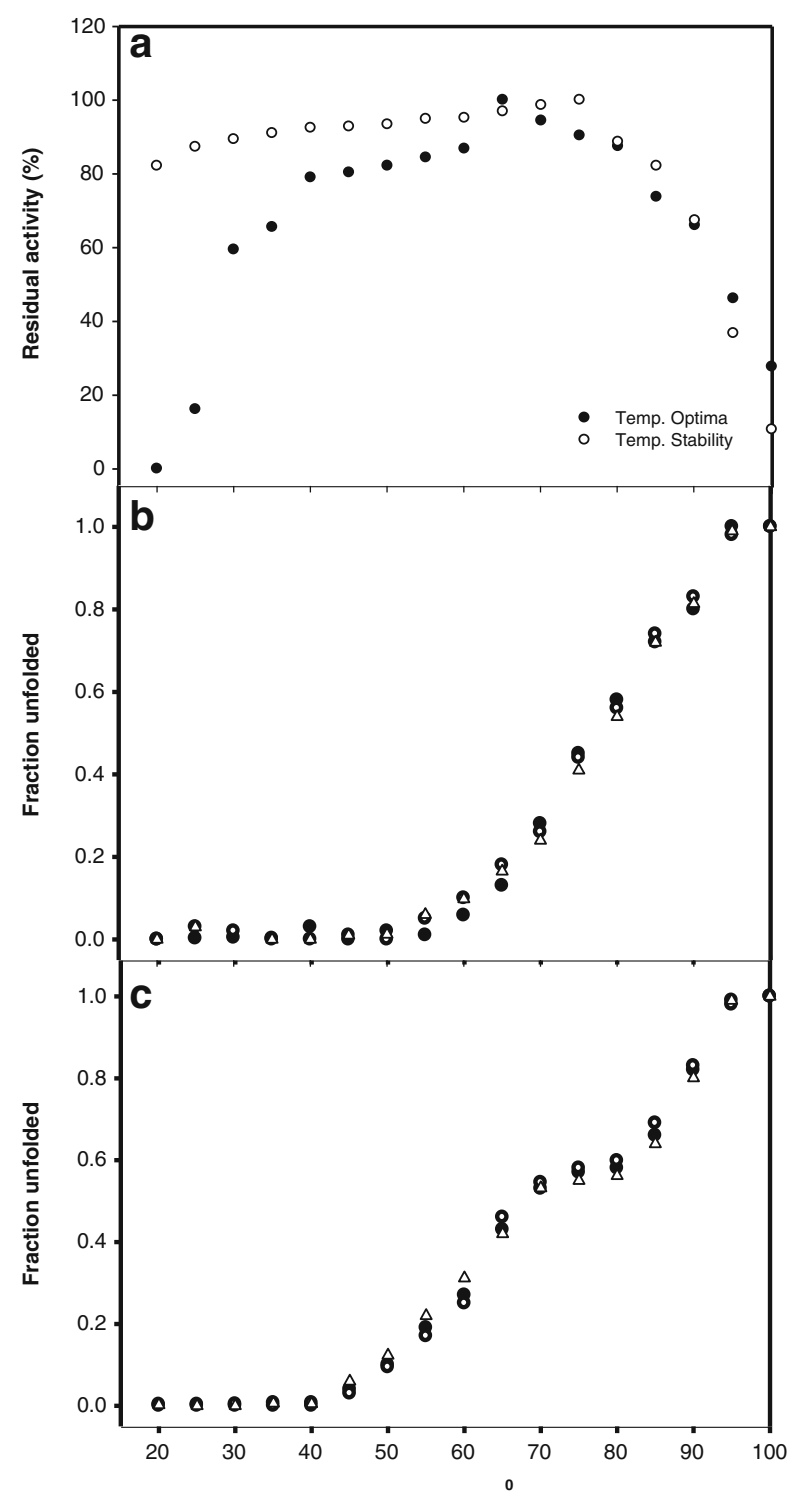

Fig. 6 Thermal-induced conformation changes of streblin. a Effect of temperature on activity (black-filled circle) and stability (open circle) of streblin. For optimum temperature, $10 \mu \mathrm{g}$ of streblin were activated at the required temperature for $15 \mathrm{~min} ; 0.5 \mathrm{ml}$ of substrate was added to it and activity was measured at the same temperature. For stability experiments, $15 \mu \mathrm{g}$ of enzyme were incubated at the required temperature for $15 \mathrm{~min}$ and activity was measured at $37^{\circ} \mathrm{C}$ and $\mathrm{pH}$ 9.0. b Temperature-induced unfolding of streblin at $\mathrm{pH} 7.0$, the unfolding transitions were followed by changes in far-UV CD (black-filled circle), fluorescence wavelength maxima (open circle) and near-UV CD (up-pointing triangle). c Temperature-induced unfolding at $\mathrm{pH} 2.0$,the unfolding transitions were followed by in far-UV-CD (black-filled circle), fluorescence wavelength maxima (open circle), and near-UV CD (up-pointing triangle)

the complete denatured state (D) with $6 \mathrm{M} \mathrm{GuHCl}, 5 \mathrm{M} \mathrm{GuHCl}$, and $4 \mathrm{M} \mathrm{GuHCl}$ from native, preMG, and MG state, respectively, no rigid structure/activity, Trp residues completely exposed to the solvent and inability of binding ANS, as shown in diagrammatic representation Fig. 7. 


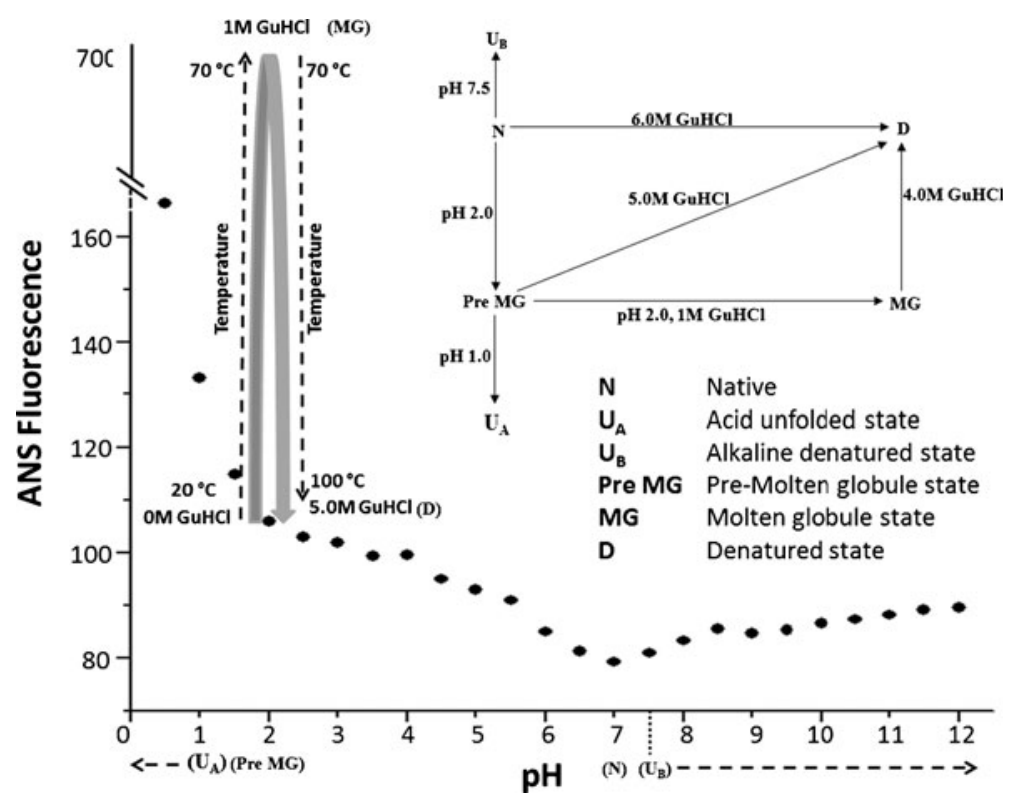

Fig. 7 Diagrammatic representation of the folding intermediates. Diagrammatic representation of intermediates formed during unfolding of streblin

At last, this study unravels the intermediate structures of streblin and calling the attention of structural biologists in understanding the structural basis of protein-protein recognition in the case of protease and physiological substrate in protease. The paradigm view can also help us to elucidate the mechanism of action and protein evolution. Since streblin has been shown to have wide range of disease modifying activity (e.g., role in cardiotonic activity, antifilarial activity, anticancer activity, antimicrobial activity, anti-allergic activity, antiparasitic activity, antibacterial activity, insecticidal activity, and also used in oral hygiene), it might have an application in pharmaceutical industries.

Acknowledgments The authors would like to acknowledge the financial assistance from CSIR/CSIR in the form of research fellowship to RK/PT respectively. Financial assistance from DBT and UGC, Government of India, for the infrastructure is also acknowledged.

Open Access This article is distributed under the terms of the Creative Commons Attribution License which permits any use, distribution, and reproduction in any medium, provided the original author(s) and the source are credited.

\section{References}

1. Privalov, P. L. (1979). Advances in Protein Chemistry, 33, 167-241.

2. Dobson, C. M. (1992). Current Opinion in Structural Biology, 2, 6-12.

3. Yang, A. S., \& Honig, B. (1994). Journal of Molecular Biology, 237, 602-614.

4. Rochet, J. C., \& Lansbury, P. T. (2000). Current Opinion in Structural Biology, 10, 60-80.

5. Stefani, M., \& Dobson, C. M. (2003). Journal of Molecular Medicine, 81, 678-699.

6. Anfinsen, C. B. (1973). Science, 181, 223-224.

7. Creighton, T. E. (1992). Protein folding. New York: Freeman.

8. Kim, P. S., \& Baldwin, R. L. (1982). Annual Review of Biochemistry, 51, 459-489. 
9. Radford, S. E. (2000). Trends in Biochemical Sciences, 25, 611-618.

10. Jackson, S. E. (1998). Folding and Design, 3, 81-91.

11. Eaton, W. A., Munoz, V., Hagen, S. J., Jas, G. S., Lapidus, L. J., Henry, E. R., \& Hofrichter, J. (2000). Annual Review of Biophysics and Biomolecular Structure, 29, 327-359.

12. Ptitsyn, O. B. (1987). Journal of Protein Chemistry, 6, 273-293.

13. Tripathi, P., Tomar, R., \& Jagannadham, M. V. (2011). Food Chemistry, 125, 1005-1012.

14. Briggs, G. S., Freedman, R. B., Goodenough, P. W., \& Sumner, I. G. (1992). Biochemical Society Transactions, 20, 2578.

15. Tiktopulo, E. I., \& Privalov, P. L. (1978). FEBS Letters, 91, 57-58.

16. Hernández-Arana, A., \& Soriano-García, M. (1988). Biochimica et Biophysica Acta, 954, 170-175.

17. Dubey, V. K., \& Jagannadham, M. V. (2003). Biochemisty, 42, 12287-12297.

18. Pace, C. N. (1990). Trends in Biotechnology, 8, 93-98.

19. Semisotnov, G. V., Rodionova, N. A., Razgulyaev, O. I., Uversky, V. N., Gripas, A. F., \& Gilmanshin, R. I. (1991). Biopolymers, 31, 119-128.

20. Balasubramanian, D., \& Kumar, C. (1976). Applied Spectroscopy Reviews, 11, 223-286.

21. Roychaudhauri, R., Sarath, G., Zeece, M., \& Markwell, J. (2003). Archives of Biochemistry and Biophysics, 412, 20-26.

22. Halfman, C. J., \& Nishida, T. (1971). Biochimica et Biophysica Acta, 243, 294-303.

23. Ptitysn, O. B. (1992) Protein Folding. In T. E. Crieghton (Ed.), W. H. Freeman New York, pp. 243-300

24. Manavalan, P., \& Johnson, W. C. (1983). Nature, 305, 831-832.

25. Sears, D. W. and Beychok, S. (1973) Physical properties and techniques of protein chemistry. In: S. J. Leach (Ed.), Academic Press, New York, pp. 445-593

26. Tanford, C. (1968). Advances in Protein Chemistry, 23, 121-282.

27. Goto, Y., \& Fink, A. L. (1989). Biochemistry, 28, 945-952.

28. Goto, Y., Calciano, L. J., \& Fink, A. L. (1990). Proceedings of the National Academy of Sciences, 87, 573-577.

29. Goto, Y., Takahashi, N., \& Fink, A. L. (1990). Biochemistry, 29, 3480-3488.

30. Uversky, V. N., Karnoup, A. S., Segel, D. J., Seshadri, S., Doniach, S., \& Fink, A. L. (1998). Journal of Molecular Biology, 278, 875-894.

31. John, B., Silva, R. D. B., \& Lala, A. K. (2001). Current Science, 80, 287-290.

32. Lakowicz, J. R. (1983). Principles of Fluorescence Spectroscopy (pp. 276-278). New York: Plenum.

33. Wong, K. P., \& Tanford, C. (1973). Journal of Biological Chemistry, 248, 8519-8523.

34. Fink, A. L., Calciano, L. J., Goto, Y., Kurotsu, T., \& Palleros, D. R. (1994). Biochemistry, 33, 12504-12511.

35. Mayr, L. M., \& Schmid, F. X. (1993). Biochemistry, 32, 7994-7998.

36. Arakawa, T., \& Timasheff, S. N. (1982). Biochemistry, 21, 6536-6544.

37. Edwin, F., Sharma, Y. V., \& Jagannadham, M. V. (2002). Biochemical and Biophysical Research Communications, 290, 1441-1446.

38. Hagihara, Y., Aimoto, S., Fink, A. L., \& Goto, Y. (1993). Journal of Molecular Biology, 231, $180-184$. 